\title{
Ocena procesu spajania elementów okapów kuchennych ze stali nierdzewnej
}

\author{
Evaluation of welded components \\ of kitchen canopies from stainless steel
}

\section{Streszczenie}

W artykule zaprezentowano wyniki badań spajania elementów wykonanych z cienkościennych blach nierdzewnych oraz dokonano oceny jakości wykonanych spoin. Próbom poddano dwie próbki wykonane z różnymi parametrami spawania.

Słowa kluczowe: spawanie laserowe; cienkościenne blachy nierdzewne

\begin{abstract}
The article presents the results of research of welding elements made of thin-walled from stainless steel sheets and contains assessment of the quality of the welds. Two samples made of various welding parameters was tested.
\end{abstract}

Keywords: laser welding; thin wall stainless steel sheets

\section{Wstęp}

W niniejszej, drugiej części artykułu przedstawiono wyniki badań własnych dotyczących spawania elementów cienkościennych wykonanych z blach nierdzewnych.

Badaniu zostały poddane spoiny wykonywane przy produkcji okapów kuchennych firmy "Akpo". Obudowy okapów produkowane są z nierdzewnej blachy stalowej 1.4016 (H17). Stal H17 jest ferrytyczną stalą chromową. Posiada dobre własności antykorozyjne, doskonale się szlifuje i poleruje, jest odporna na działanie wody, pary wodnej, słabych kwasów i alkoholi. Jest plastyczna, po gięciu nie powstają rozwarstwienia, dzięki czemu jest chętnie wykorzystywa-

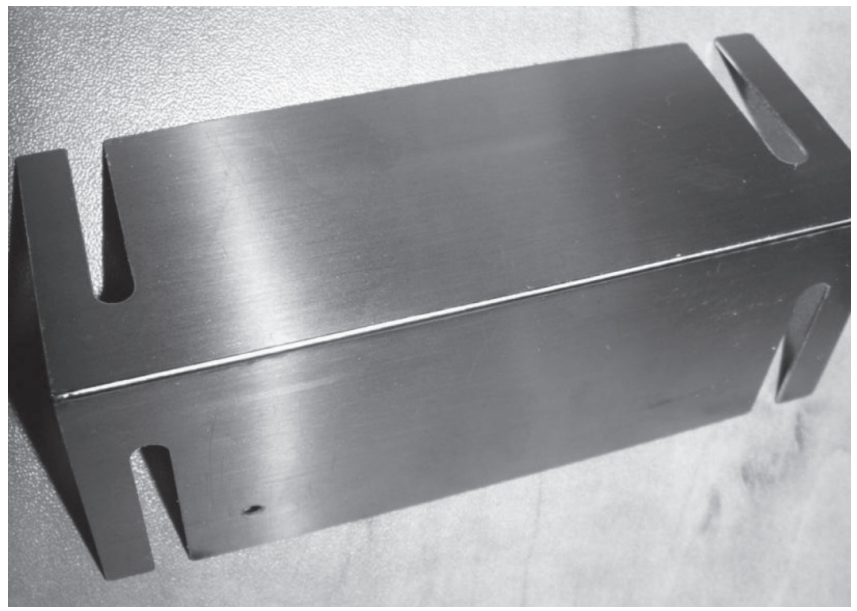

Rys. 1. Widok połączenia próbnego dwóch płaszczy blachy (źródło: opracowanie własne)

Fig. 1. General view of the connecting test two sheets steel (source: own case study) na do produkcji sprzętu gospodarstwa domowego, w lokalach gastronomicznych, w branży spożywczej, meblarskiej, technice medycznej, przemyśle chemicznym. Stal 1.4016 jest oferowana głównie w postaci blach o powierzchni BA polerowanej, zabezpieczona folią ochronną. Skład chemiczny, właściwości wytrzymałościowe i fizyczne powodują, że spawanie tego materiału nie jest zalecane. Szczególnie trudne okazuje się spawanie tradycyjnymi metodami łukowymi blach o grubościach nieprzekraczających $0,8 \mathrm{~mm}$. Spawanie takie powoduje przepalenia, pofalowania, silne przebarwienia okolic SWC oraz liczne pory powierzchniowe. Dodatkowo po spawaniu zaleca się wyżarzanie w temperaturze $600-800{ }^{\circ} \mathrm{C}$, co w przypadku produkcji AGD nie jest możliwe. Dlatego też współcześnie do łączenia płaszczy blachy wykorzystuje się zrobotyzowane spawanie współpracujące z laserowymi źródłami energii. Przykład takiego połączenia pokazano na rysunku 1 .

\section{Badania próbki 1}

Poniżej opisano spoinę wykonaną z następującymi parametrami:

- moc: $P=800[W]$,

- grubość materiału: 0,8 [mm],

- koncentracja źródła światła: $F=8$,

- prędkość spawania: $\mathrm{v}_{\mathrm{sp}}=0,018[\mathrm{~m} / \mathrm{s}]$.

W trakcie kontroli jakości złącza nie stwierdzono wad. To, co najbardziej widoczne w wyrobie (rys. 2, powiększenie 50-krotne), czyli lico połączenia płaskie, bardzo gładkie, regularne, bez podtopień. Całkowity brak przebarwień w okolicy SWC.

Dr hab. inż. Tadeusz Sałaciński, prof. PW - Politechnika Warszawska; mgr inż. Wojciech Sosnowski - Prod-Met Sp. z o.o.

Autor korespondencyjny/Corresponding author. mail wojtek.sosnowski@o2.pl 
Na rysunku 3 pokazano przekrój spoiny wykonanej ze 100 krotnym powiększeniem. Widoczne są bardzo regularne kryształy spoiny, znacznie większe od kryształów materiału rodzimego. Osie kryształów ustawione zgodnie z kierunkiem zastygania. Struktura ferrytyczna. Lico w tym miejscu przekroju lekko pofałdowane. Bardzo wyraźna linia wtopienia w lekko zielonkawym kolorze. Przesunięcie płaszczyzn łączonych blach (w poziomie) na około $20 \mu \mathrm{m}$ ( ok. 2,5\%). W tej części spoiny brak przetopu na grubości nieco powyżej $100 \mu \mathrm{m}$ co stanowi ok. 13\% grubości złącza. Wąska, prawie niewidoczna, strefa wpływu ciepła.

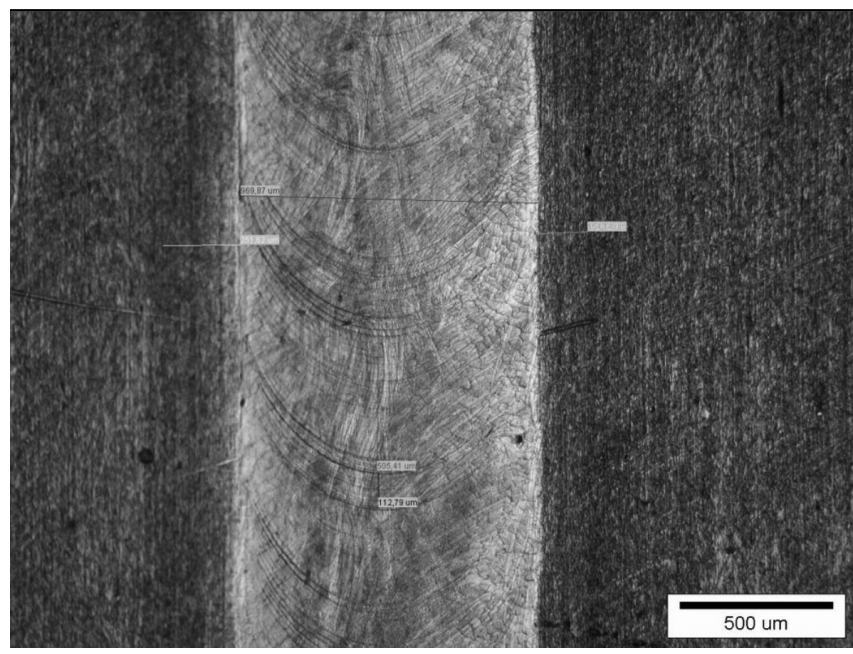

Rys. 2. Zdjęcie makro próbki od strony lica (źródło: opracowanie własne)

Fig. 2. Macro photography of samples from weld face side (source: own case study)

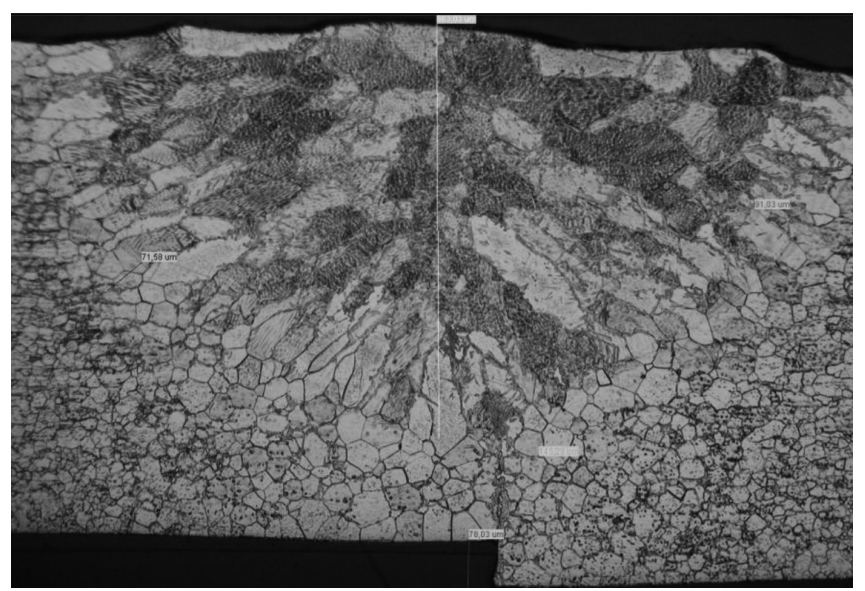

Rys. 3. Widok przekroju spoiny - powiększenie 100-krotne (źródło: opracowanie własne)

Fig. 3. View of cross section of weld joint - magnified 100 times (source: own case study)

W tym fragmencie przekroju zauważono również pionowe przesunięcie składanych płaszczy blachy wynikłe z różnej siły docisku w oprzyrządowaniu, które wprawdzie nie przekraczało $70 \mu \mathrm{m}$, ale dodatkowo wpływa na wielkość braku przetopu, a tym samym na wadliwość złącza. Lico spoiny ma szerokość ok. $900 \mu \mathrm{m}$. Widoczna z prawej strony wyraźna krawędź wskazuje na to, że w tym miejscu nastąpiło przesunięcie osi promienia laserowego w stosunku do osi łączonych elementów, czego wynikiem jest brak przetopu, będący wadą spawalniczą.

Rysunek 4 przedstawia zdjęcie omawianej próbki wykonane od strony grani spoiny z 50-krotnym powiększeniem. Wyraźna, równa krawędź w miejscu złączenia, potwierdza brak przetopu. Od tej strony wyraźnie widoczna SWC. Widoczne

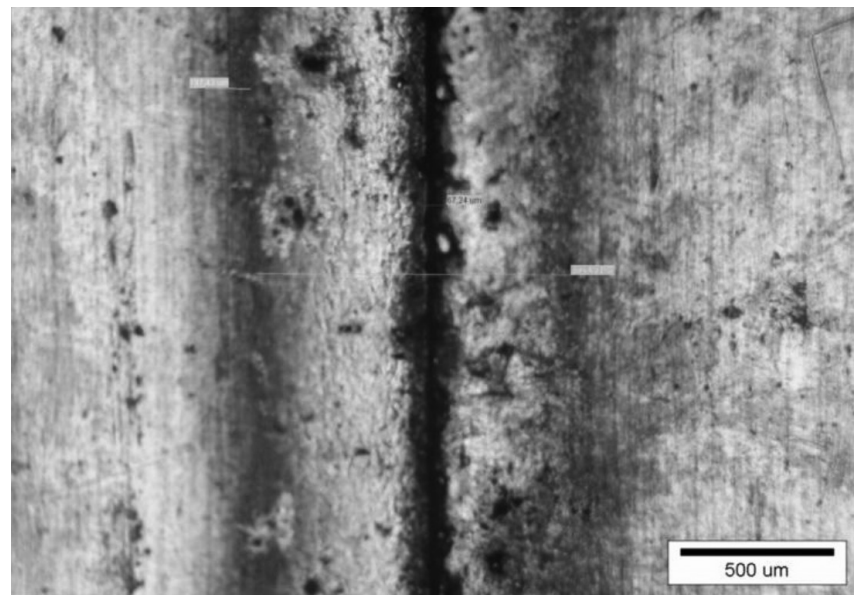

Rys. 4. Widok próbki od strony grani (źródło: opracowanie własne) Fig. 4. View of sample from weld root side (source: own case study)

są również przebarwienia termiczne od strony wewnętrznej okapu spowodowane znaczne mniejszym strumieniem gazu osłonowego chłodzącego złącze. Brak przetopu grani sprawia, że złącze jest wadliwe konstrukcyjnie. W przypadku okapów kuchennych wady takie są dopuszczalne, ponieważ złącza te nie przenoszą obciążeń zarówno statycznych, jak i dynamicznych, nie wpływają w sposób znaczący na wytrzy-
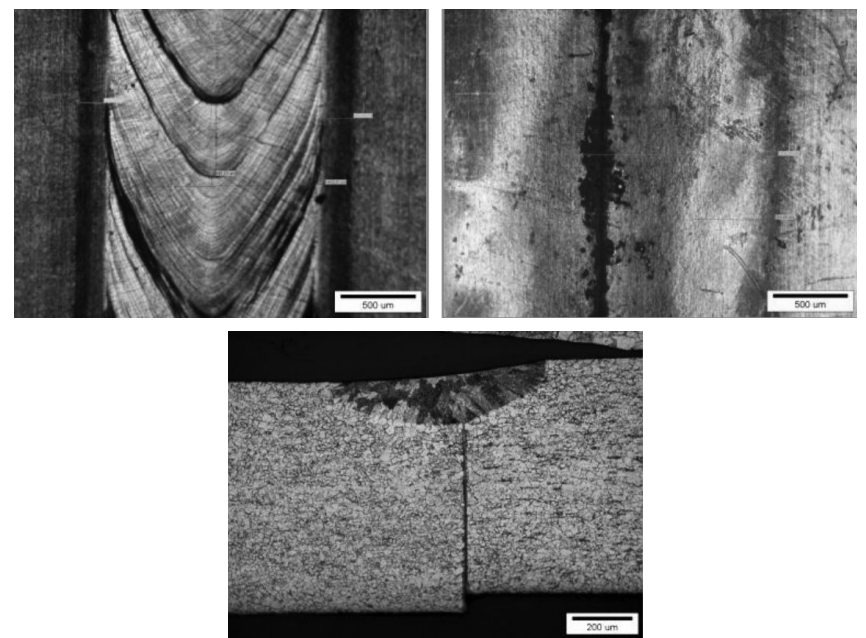

Rys. 5. Próbka 2; a) lico, b) grań, c) przekrój mikro, powiększenie 100-krotne (źródło: opracowanie własne)

Fig. 5. Sample 2; a) weld face side, b) weld root side, c) micro crossection view, magnified 100 times (source: own case study)

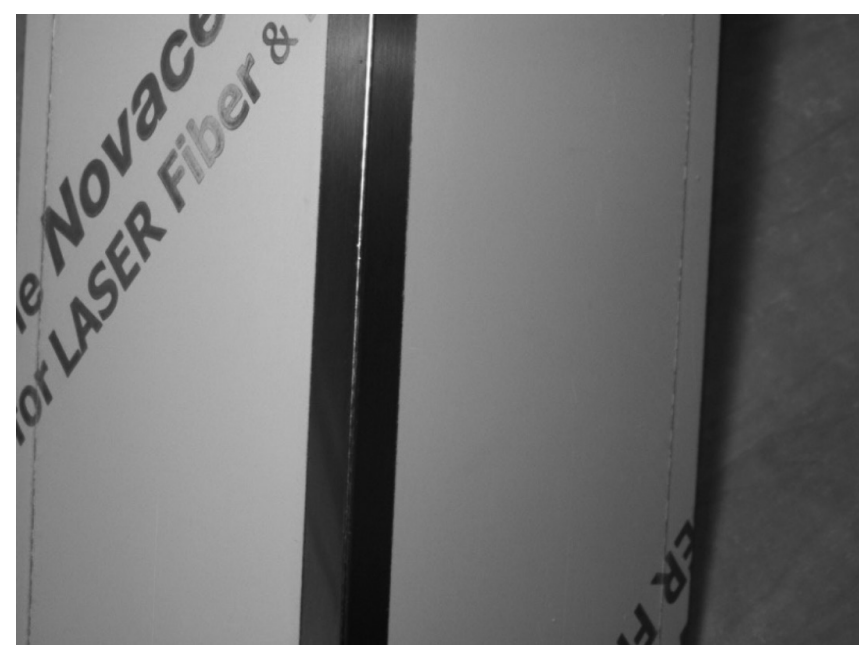

Rys. 6. Próbka 3; złącze z pełnym przetopem (źródło: opracowanie własne)

Fig. 6. Sample 3; welded joint with full penetration (source: own case study) 
małość połączeń, a ujawniają się dopiero po badaniu metalograficznym. Nie są widoczne gołym okiem i nie wpływają na obniżenie estetyki wyrobów.

\section{Badania próbki 2}

Poniżej opisano spoinę wykonaną z następującymi parametrami:

- moc: $P=800[W]$,
- grubość materiału: 0,8 [mm],

- koncentracja źródła światła: $F=4$,

- prędkość spawania: $\mathrm{v}_{\mathrm{sp}}=0,04[\mathrm{~m} / \mathrm{s}]$.

Na rysunku 5 przedstawiono inne złącze próbne, wykonane $z$ parametrami spawania, odbiegającymi od zalecanych przez producenta. Faktura lica charakteryzuje się "grubymi" łuskami. Zwiększenie prędkości spawania do $0,04 \mathrm{~m} / \mathrm{s}$ spowodowało, że przetopienie wystąpiło na grubości ok. $150 \mu \mathrm{m}$. Tego typu złącze w większości przypadków pęknie w momencie montażu.

\section{Wnioski}

Wyniki badań metalograficznych połączeń spawanych wiązką laserową, ocena wizualna ich jakości, a także badanie mikrotwardości, wykazały, że:

- złącza charakteryzują się gładkim, równomiernym licem,

- strefa wpływu ciepła jest mało widoczna na długości całego złącza od strony lica,

- w większości przypadków szerokość lica spoiny zbliżona jest do grubości łączonych elementów,

- badanie mikrotwardości wykazało znacznie mniejszą twardość w obrębie spoiny niż w materiale rodzimym,

- mikronierówności powstałe po cięciu mają znaczący wpływ na niewspółosiowość łączonych elementów z przebiegiem wiązki laserowej,

- dobrane parametry nie pozwalają na przetopienie całej grubości łączonego materiału, co powoduje, że są one wadliwe konstrukcyjnie.

We wszystkich próbach przeprowadzonych zgodnie z zaleceniami producenta lasera nie uzyskano całkowitego przetopu materiału przy jednym przejściu głowicy robota spawalniczego. Próby doświadczalne wykonane w zakładzie wskazują, że całkowity przetop dla tej grubości materiału można uzyskać jedynie przez zastosowanie spoiny dwuściegowej, dwuwarstwowej.

\section{Literatura}

[1] Ferenc K.: Spawalnictwo. WNT. Warszawa, 2007.

[2] Klimpel A.: Spawanie, zgrzewanie i cięcie metali. WNT. Warszawa, 1999.

[3] Chmielewski T.: Projektowanie procesów technologicznych - spawalnictwo. OWPW. Warszawa, 2013.
[4] Poradnik inżyniera. Spawalnictwo. WNT. Warszawa, 2005.

[5] Tasak E.: Metalurgia spawania. Wyd. JAK. Kraków, 2008.

[6] Sałaciński T.: Inżynieria jakości w technikach wytwarzania. OWPW. Warszawa, 2016. 